\title{
THE PEACEFUL USES OF ATOMIC ENERGY
}

\author{
THE GENEVA INTERNATIONAL CONFERENCE
}

\author{
By SIR JOHN COCKCROFT, K.C.B., C.B.E., F.R.S.
}

\section{$\mathrm{T}$} HE Geneva Conference on the Peaceful Uses of Atomic Energy organized by the United Nations Organization has been a remarkable experience for those fortunate in participating. It was attended by 1,400 delegates and observers from seventy-three countries. More than a thousand papers were prepared for the Conference, of which 450 were read.

The more general topics such as the future requirements for energy and the role of nuclear power were discussed in three days of plenary sessions. This was followed by nine days of technical discussions going on from 9 a.m. to 5.30 p.m. in three parallel sessions for reactor technology, chemical and metallurgical technology and biology and isotopes. Adequate time was allowed for presentation of the papers, which were simultaneously translated into four languages, and discussion periods of ten minutes or so were fully used.

Besides these, innumerable detailed discussions proceeded in the broad corridors of the Palais des Nations, which is conveniently provided with comfortable seats ideal for such a purpose. Advantage was also taken of the unique gathering of distinguished scientists to arrange many informal seminars. Thus a whole-day seminar on field theory was attended by theoretical physicists from the United States, the United Kingdom and the U.S.S.R. and many other countries, and was the first occasion on which Russian and Western physicists have met for discussion of this subject since 1937. Prof. E. O. Lawrence and Prof. V. I. Veksler attended seminars on high-energy accelerators following the evening lectures which they gave on their own accelerator work. The scientific and technical activities were supplemented by innumerable receptions, lunches and dinners, so that every available minute was occupied from 9 a.m. until midnight, and the Conference was a test of physical fitness unparalleled in our experience.

The main weight of the papers in the sessions on reactor tochnology and chemical and metallurgical technology came from Britain, the U.S.S.R. and the United States, though there were many valuable contributions from other countries. The Conference led to a lifting of the veil over the atomic energy programme of the U.S.S.R. and coincided with the coming into effect of a revised declassification policy of Britain, Canada and the United States, decided in principle nine months ago.

So we heard a large number of valuable papers on research reactors and power reactors and their associated technology. From the nine hundred or so possible types of power reactors in Dr. A. M. Weinberg's classification, about twelve have been selected for construction in experimental or prototype form by five nations. Thus graphite-moderated reactors using gas, water or liquid sodium for cooling are being built by Britain and France, the U.S.S.R. and the United States, respectively.

Water-moderated reactors using solid fuel are being studied in four types using light or heavy water, and in designs in which the water boils and is transmitted direct to a turbine or in which the water circulates through a heat exchanger to raise steam. Homogeneous thermal reactors were described in at least three forms, while experimental fast reactors are being built by both the United States and the United Kingdom.

Prof. D. V. Blokhintsev, who is head of the Institute of the Academy of Sciences of the U.S.S.R. devoted to reactor development, described the first Russian water-cooled graphite-moderated power station, which has been operating for a year and produces 5,000 kilowatts of electricity. The power reactor was designed on severely practical lines with no regard for neutron economy, since uranium fuel containing 5 per cent of uranium-235 enclosed in stainless steel tubes constitutes the fuel element. So fuel costs are very high, and the regeneration of secondary plutonium fuel is low. The reactor has proved to be very reliable in operation and is providing experience from which a 100-megawatt reactor is now being built. This reactor will also use highly enriched fuel and is expected to produce power at a cost of 10-20 kopecks per unit, as compared with an average price for conventional stations of 10 kopecks. Other types of power reactors are being experimented with, including fast reactors; but the state of development appears to be behind American and British progress.

The American papers on power reactors and nuclear technology show a very broad development in this fiold. Very detailed papers were presented on the American pressurized water reactor which is to develop more than 60 megawatts, the sodium-graphite reactor developing 75 megawatts, the boiling heavywater reactor developing 180 megawatts, the homogeneous aqueous and liquid metal-fuelled reactors and the sodium-cooled 62-megawatt (fast) experimental breeder reactor. These papers were supplemented by most interesting models in the exhibition at the Palais des Nations, together with specimens of the fuel elements to be used.

These reactors form part of the American fiveyear programme of experimental and demonstration power reactors which will be completed by 1960 , so that by then the United States will be generating 700 megawatts of electricity from nuclear stations.

Britain presented papers on the engineering details of the Calder Hall graphite-moderated gas-cooled reactor and the Dounreay fast reactor. Models of these reactors were shown in the exhibition, together with a most interesting colour film on the building of the Calder Hall reactor. Britain also contributed many papers on reactor technology. One of the most interesting described the results obtained with the zero-energy fast reactor-ZEPHYR-which showed that in a plutonium-fuelled zero-energy fast reactor, for each plutonium atom destroyed in the core, two new plutonium atoms are produced in the blanket. Fission of the uranium-235 in the blanket plays an 
important part. The full-sized fast reactor will not realize the full theoretical breeding gain, owing to absorption of neutrons by coolant and other materials. Nevertheless, high-gain factors seem assured, and Dr. W. H. Zinn predicts a breeding gain of 60-70 per cent with the American plutonium-uranium-238 experimental breeding reactor, leading to a time to double the fuel investment of five to six years.

The aqueous homogeneous breeding reactor using the thorium - uranium-233 fuel cycle was predicted to have a breeding gain of 10-15 per cent, together with very high outputs per kilogram of fuel and comparatively low capital costs. The uranium-238plutonium fuel cycle does not promise breeding in the thermal region. Since thorium has also favourable properties metallurgically, its use in thermal reactors seems likely to be generally important in the second decade.

Our best view of Russian nuclear technology was in the field of nuclear constants. The nuclear data obtained by the U.S.S.R., Britain, the United States and France have all been plotted on a common basis and show very good agreement, showing that Russian techniques and instruments are as highly developed as those in Britain and the United States.

The papers on the economics of nuclear power showed a general consensus of opinion that capital costs of nuclear power stations will be appreciably higher during the next decade than those of conventional power stations. Typical values were $£ 120$ per kilowatt for a 150-megawatt gas-cooled graphite reactor ; 250 dollars per kilowatt for a 250-megawatt heavy-water reactor; 200 dollars per kilowatt for a 75-megawatt sodium-graphite reactor. The first figure is based on the construction cost of Calder Hall; the last three on design studies only. Fuel costs were predicted to be lower than for conventional stations; but this depends largely on the 'burn-up' of the uranium-235 which is achieved. Prediction of heat extraction per ton of uranium varied from the equivalent of 10,000 tons of coal to more than three times this figure. But little experimental evidence is yet available.

The figure for the overall cost of nuclear power depends a great deal on the interest rate assumed. The Americans use high capital charges-of the order of 12 per cent-and their forecast overall production costs during the next decade lie between 7 and 10 mills, while the great bulk of their power is generated at about 5 mills. In Britain nuclear power is quasicompetitive.

The forecasts of the proportion of electricity to be generated by nuclear power in 1975 varied, from 40 per cent in Britain to an American figure lying between 1 per cent and 15 per cent, depending on whether costs are 9 mills a unit or 6 mills a unit at that time. The Canadian position seems to be rather similar. Forecasts of the usage in other countries by 1975 varied greatly, depending on the amount of hydroelectricity still to be developed and its capital cost and location. Most Western European countries will not require appreciable amounts of nuclear power before 1965 .

Dr. H. J. Bhabha's paper on India's energy requirements showed that 80 per cent of the energy comes from the burning of dung. The energy consumption per head is one-tenth of that of Britain, and electricity consumption one-eightieth. This is planned to increase seven-fold by 1975 , so electrical capacity will have to increase from $3 \frac{1}{2}$ million kilowatts to 25 million kilowatts. The undeveloped hydroelectric capacity of $\mathbf{3 5}$ million kilowatts could provide most of this; but there are some areas far from hydroelectric sources where thermal power stations are at present used, and here nuclear energy will play a part. India is especially interested in the use of thorium.

Papers on the power requirements in other 'underdeveloped countries' showed a need for power reactors developing about 10 megawatts of electricity. These may also find applications in remote mining areas. Power costs in many of these areas are already much higher than normal costs--up to four times higher. Power from small units will necessarily be higher in cost; but papers presented by the United States suggest that a reactor of the boiling-water type could probably produce power at 15 mills, which is almost competitive with commercial 10-megawatt power stations.

It appears, however, that a much more detailed 'market survey' of the power needs and requirements of these countries is required before we can assess the volume of applications in the next two decades.

The position at the end of the century is easier to assess, since the economists and statisticians agreed in predicting a minimum energy requirement of 7 or 8 billion tons of coal-equivalent by the year 2000 , of which half would be required for generating electricity. Hydroelectricity is predicted to supply 1 billion tons equivalent, and it is hoped that nuclear energy would by then be able to do the work of 2-3 billion tons of coal a year. The forecast of British requirements for nuclear energy at that time is about a tenth of this figure.

Papers on the occurrence of uranium and thorium suggest that in the 1960's plenty of fuel will be available at a cost of about 10 dollars a $\mathrm{lb}$. Supplies of at least one million tons were reported to be available and, if by the end of the century breeding is achieved, only a few thousand tons of uranium and thorium a year are required to undertake the predicted task of the economist.

The biological sessions discussed the hazards of radiation to workers in the atomic energy industry and to the general public. The excellent work done by the International Commission on Radiological Protection in determining safe levels of radiation and safe amounts of radioactive materials was described, and it was agreed that these recommendations ought to be incorporated into world-wide codes of practice. The World Health Organization undertook to help countries new to atomic energy development. The genetic problems of radiation were also discussed in brief sessions, and there was agreement about the inadequate experimental data and the need for increasing the scale of experimental work. Besides the United States and Great Britain, several other countries will undertake experimental work. The work is, however, expensive, and may easily cost $£ 100,000$ per annum if significant results are to be achieved within ten years.

Numerous papers were presented describing the applications of radioactive isotopes to biology, medicine and industry.

An interesting picture of the state of development of Russian pure nuclear physics was revealed by Prof. Veksler's evening lecture on high-energy particle accelerators. The U.S.S.R. now have the highest-energy synchro-cyclotron in the worldproducing 660 -million volt protons. They have also nearly completed a 10-billion volt proton synchrotron. This accelerator is of a similar design to the 
Berkeley 6-billion volt bevatron. It uses 36,000 tons of steel in a magnet having an air gap of $2 \mathrm{~m}$. $\times$ $40 \mathrm{~cm}$.; so for the next three or four years the U.S.S.R. will have more powerful machines than the United States. Britain is now far behind both countries in its equipment and work in this most important field of nuclear physics.

In general, we have gained the impression that the U.S.S.R. have an enormous deployment of scientific effort in the field of atomic energy, and that their output of scientists and technologists from their universities is quite adequate to maintain this without starving other activities.

The Conference has been more successful than we had dared to hope from such a large gathering. It has brought together East and West after a long period of separation in the physical sciences. It has been a meeting ground for innumerable friends from all parts of the world. It has enabled us to discuss how best we can help other countries, and has done a great deal to re-establish the normal pattern of communication in the scientific world.

\title{
THE CULCHETH LABORATORIES OF THE UNITED KINGDOM ATOMIC ENERGY AUTHORITY INDUSTRIAL GROUP
}

\author{
By Dr. A. B. McINTOSH
}

$\mathrm{T}$ HE White Paper, "A Programme of Nuclear Power" (Cmd. 9389), has directed attention to the work of the Atomic Energy Authority composed of the Weapons Group (A.W.R.E.), the Research Group (A.E.R.E.) and the Industrial Group. Each is represented by a member of the executive under the chairmanship of Sir Edwin Plowden.

Under Sir Christopher Hinton, its managing director, the Industrial Group is responsible for the design, construction and operation of plants for the production of fissile material and for the prototype nuclear power stations at Calder Hall and Chapel Cross. It is also responsible for advice and guidance to the industrial firms which will undertake the construction of the power stations for the Central Electricity Authority proposed in the White Paper. In collaboration with Harwell, it also pioneers new types of reactors in conformity with the policy laid down in the White Paper.

Within the Industrial Group there are three technical branches: Engineering, Operations, and Research and Development, each under its own director. The design and construction of such projects as the reactors at Calder Hall, Chapel Cross and the large experimental fast reactor at Dounreay are the responsibility of the Engineering Branch. On completion of the plants, the Operations Branch becomes responsible for operation and level of production.

The responsibility of the Research and Develop. ment Branch under its director, Mr. L. Rotherham, is: (1) removal of difficulties which may impede the attainment of full production in any part of a production plant and the development of works processes; (2) provision of information to support the design of now plants and prototype reactors; (3) longer-term study of problems which arise from production plants and design studies.

The Branch works in close collaboration with the Research Establishment at Harwell, which under. takes part of the work.

In the Research and Development Branch, the emphasis is always on the technique at a particular date, and all work is planned and progressed in the same way as the engineering construction programmes to which the major part is intimately linked. It is research applied to industrial needs and not pure research, but in all its work there is close coordination and collaboration with the Research Group at Harwell. This is especially important in the earliest stages, when the feasibility of future reactor systems is being studied.

There are at present four laboratories in the Research and Development Branch, with a fifth in course of formation for work on the Dounreay site. In each of the laboratories there is a large measure of local autonomy and authority. At the Industrial Group Headquarters at Pisley there is a section of the Research and Development Branch working in close collaboration with the design engineers and the headquarters organization of the Operations Branch. Part of the responsibility of this section is that of carrying out theoretical calculations for the four existing laboratories at Capenhurst, Windscale, Springfields and Culcheth.

Except for some specialized fields in which Harwell is responsible, these laboratories, with a scientific and experimental complement of approximately eight hundred, provide a development effort for sanctioned construction projects which are the commitments of the Industrial Group. The Capenhurst Laboratory deals mainly with problems of an engineering nature, such as fluid flow and heat transfer. At Windscale the laboratories are largely devoted to radioactive chemistry, metallurgy and physics, arising from reactor problems at Windscale and Calder and the chemical problems of the plutonium separation process. In Culcheth there is a responsibility for the selection of reactor materials and for work on the extraction of these materials where they may not be commercially available. The small-scale work carried out at Culcheth is then extended to a larger scale at the Springfields Laboratory, which is responsible for the development of fuels and fuel elements.

Culcheth is the only laboratory not on a works site; but it is associated very closely with the Engineering Design Branch at Risley. This gives the laboratories a responsibility for the initiation of work at the feasibility and planning stage of new reactors, especially in the selection of materials for reactor components.

To carry out the commitments of the White Paper, increases in staff in the Research and Development Branch of the Industrial Group are necessary. The Culcheth Laboratories have a present complement of approximately 160 scientific and experimental staff. They are extensively equipped with all the tools required for modern metallurgical research and include laboratories specializing in X-ray diffraction techniques, electron microscopy and ceramics. How- 